\title{
Correction to: Analysis of Draft Force Requirement of a Compact Disc Harrow and Model Development for Future Predictions
}

\author{
Frank Gyan Okyere ${ }^{1}$ - Waqas Qasim ${ }^{1}$. Jayanta Kumar Basak ${ }^{1} \cdot$ Fawad Khan $^{1} \cdot$ Yong Jin Lee $^{1} \cdot$ Jihoon Park $^{1}$. \\ Elanchezhian Arulmozhi ${ }^{1}$ - Yong Cheol Yoon ${ }^{2}$. Dae Sik Kang ${ }^{3} \cdot$ Hyeon Tae Kim ${ }^{1}$
}

Published online: 27 November 2019

(C) The Korean Society for Agricultural Machinery 2019

Correction to: Journal of Biosystems Engineering (2019)

44:47-56

https://doi.org/10.1007/s42853-019-00003-3

Due to an unfortunate oversight, Table 8 has been shown erroneously.

The authors apologize for this mistake.

Table 8 Paired sample $t$ test of predicted and measured draft force

\begin{tabular}{llllll}
\hline Variables & Mean difference $(N)$ & $P$ value & $95 \%$ confidence interval $(N)$ & Correlation coefficient & Mean $(N)$ \\
\cline { 3 - 5 } & & & & F4 draft force & Predicted \\
\hline Predicted vs F4 draft force $(N)$ & 1.306 & 0.977 & -89.20 to 91.81 & 0.7 & 914.5 \\
\hline
\end{tabular}

The online version of the original article can be found at https://doi.org/ 10.1007/s42853-019-00003-3

Hyeon Tae Kim

bioani@gnu.ac.kr

1 Department of Bio-Industrial Machinery Eng, Gyeongsang National

University (Institute of Agriculture \& Life Science), Jinju 52828,

Republic of Korea

2 Department of Agri. Eng, Gyeongsang National University (Institute of Agriculture \& Life Science), Jinju 52828, Republic of Korea

3 Green Max Co. Ltd, Incheon 21700, Republic of Korea 